\title{
Bilateral breast abscess in a neonate - A case report
}

\author{
Arulkumaran Arunagirinathan, Jeyakumari Duraipandian \\ Gopal Rangasamy, Smita Shivekar, Prachi saban, Sunil Shivekar
}

\begin{abstract}
Introduction: Neonatal mastitis and breast abscesses are uncommon. The most common causative agent is Staphylococcal aureus. Case Report: A case of bilateral breast abscess due to Methicillin resistant staphylococcus aureus (MRSA) in a 11-day-old newborn baby, which responded well to surgical drainage and injection vancomycin is reported due to its rare presentation. Conclusion: Complications of neonatal mastitis are rare but have been reported. It is therefore essential to treat neonatal breast abscess aggressively including antibiotics and surgical drainage.
\end{abstract}

Keywords: Breast abscess, Mastitis, Neonates, MRSA

$* * * * * * * * *$

Arulkumaran Arunagirinathan ${ }^{1}$ Jeyakumari Duraipandian $^{2}$, Gopal Rangasamy², Smita Shivekar ${ }^{3}$, Prachi saban ${ }^{3}$, Sunil Shivekar ${ }^{3}$

Affiliations: ${ }^{1}$ Associate Professor, Department of Pediatrics, Sri Manakula Vinayagar Medical College and Hospital, Madagadipet, Puducherry, India; ${ }^{2}$ Professor, Department of Microbiology, Sri Manakula Vinayagar Medical College and Hospital, Madagadipet, Puducherry, India; ${ }^{3}$ Assistant Professors, Department of Microbiology, Sri Manakula Vinayagar Medical College and Hospital, Madagadipet, Puducherry, India.

Corresponding Author: Dr. Jeyakmari Duraipandian, Professor, Department of Microbiology, Sri Manakula Vinayagar Medical College and Hospital, Madagadipet, Puducherry -605107, India; Phone: 91- 9865587080; Office: 91-0413- 2643000-2031; Fax: 91-0413-2643014;

Email: karailabscuddalore@yahoo.co.in

Received: 26 January 2011

Accepted: 04 April 2011

Published: 31 May 2011
Arunagirinathan A, Duraipandian J, Rangasamy G, Shivekar S, Saban P, Shivekar S. Bilateral breast abscess in a neonate - A case report. International Journal of Case Reports and Images 2011;2(5):26-28.

$* * * * * * * * *$

doi:10.5348/ijcri-2011-05-35-CR-5

\section{INTRODUCTION}

Neonatal breast enlargement is common and probably due to fall in the level of maternal oestrogen at the end of pregnancy which triggers the release of prolactin from the pituitary gland of the newborn [1]. It is often self limiting. Neonatal mastitis and breast abscess are uncommon. Manipulation of the breast tissue can lead to mastitis and breast abscess [2]. Early cases of mastitis usually resolve with use of antibiotics but when abscess is formed surgical drainage is needed. Infection is localized but can lead to cellulitis, fasciitis, osteomyelitis, brain abscess and generalized sepsis [3].

\section{CASE REPORT}

A 11-day-old female baby was admitted with complaints of swelling of both breasts of three days duration and fever of two days duration. The swelling was noted by the mother initially on the right side and later on the left side (Figure 1). The child was a full term normal baby delivered vaginally. The first week of neonatal period was normal. Swelling was noted initially on day eight around the right breast spreading to adjacent areas of the chest and followed by swelling of the left breast.

On examination at admission the child was febrile but active with swelling of both the breasts. The swelling on the left side was fluctuant. The abscess 
was incised and $50 \mathrm{ml}$ of pus drained and sent for culture and sensitivity (Figure 2A, B). The patient was empirically put on injection augmentin and amikacin. Culture of the aspirated pus yielded a pure growth of MRSA which was sensitive to vancomycin, linezolid and erythromycin and resistant to penicillin, oxacillin, ciprofloxacin and co-trimoxazole. Blood culture was sterile at $72 \mathrm{hrs}$ of incubation. Total count of WBC was $43,200 / \mathrm{cmm}$ with polymorphs - 50\%, lymphocytes $45 \%$, monocytes - $4 \%$ and eosinophils - $1 \%$, hemoglobin, platelet count, urea, creatinine, glucose were normal. C-reactive protein level was raised. The patient was put on injection vancomycin intravenously, 8-hourly following the issue of culture report and continuing profuse discharge of pus. The discharge of pus gradually decreased on left side within the next seven days. The residual abscess on the right side was drained surgically. The discharge ceased on right side after one week following the drainage. The child was discharged with complete cessation of pus from both the breasts after treatment with injection vancomycin for ten days and surgical drainage. The child was active and feeding well and afebrile at the time of discharge. Papular lesions were seen over the trunk on the tenth day of discharge which was diagnosed as "Erythema toxicum" by the dermatologist and advised topical application of calamine lotion. The child was discharged with advice to be brought for review after a week. The child was healthy and had no discharge of pus during the review seven days after discharge.

\section{DISCUSSION}

Neonatal breast abscess is uncommon and usually unilateral with no systemic symptoms. In the present case the patient was febrile which is rare as reported by Rudoy in their study of a series of cases [4]. Neonatal mastitis is seen in term infants with a peak incidence at approximately three weeks of age.

The most common causative agent is Staphyloccocus aureus [3] as was the case in our patient. Bilateral involvement is uncommon and fever is seen in less than $50 \%$ of patients and leucocytosis in less than $75 \%$ of patients $[4,5,6]$. Our patient had fever, leucocytosis and bilateral involvement of breast. Early cases of mastitis usually resolve with use of antibiotics but when an abscess is formed surgical drainage is needed [5]. Aspiration was done in addition to use of antibiotics as the abscess failed to resolve with antibiotics alone. Complications of neonatal mastitis are rare but cellulitis, fasciitis, osteomyelitis, brain abscess and sepsis have been reported [3].

\section{CONCLUSION}

It is therefore essential to treat neonatal mastitis aggressively with antibiotics including surgical drainage in refractory cases [5] as in our patient to

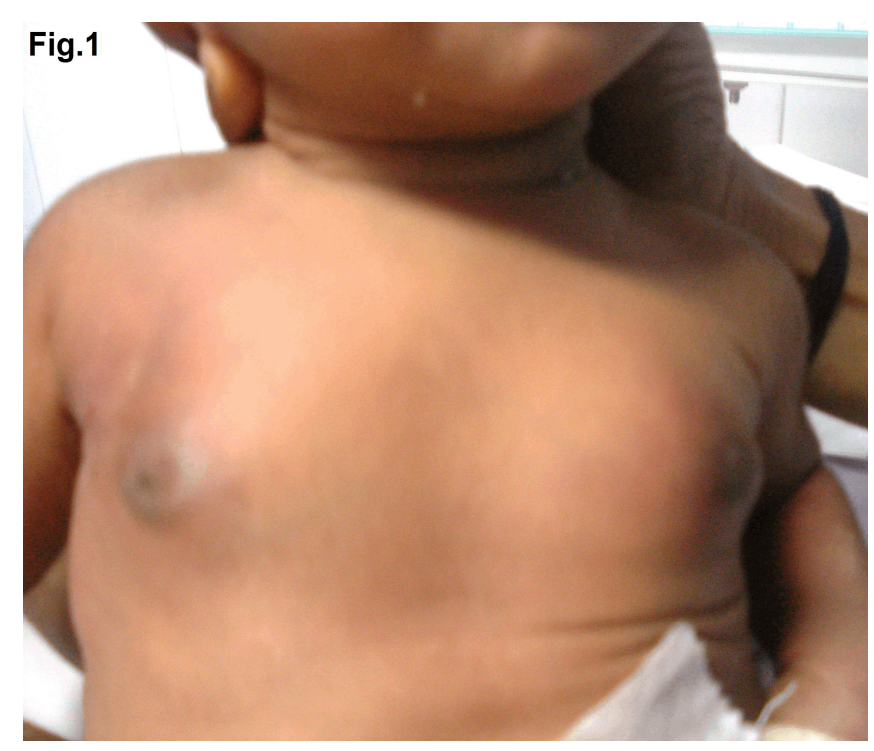

Figure 1: Inflammation and swelling of both the breasts.

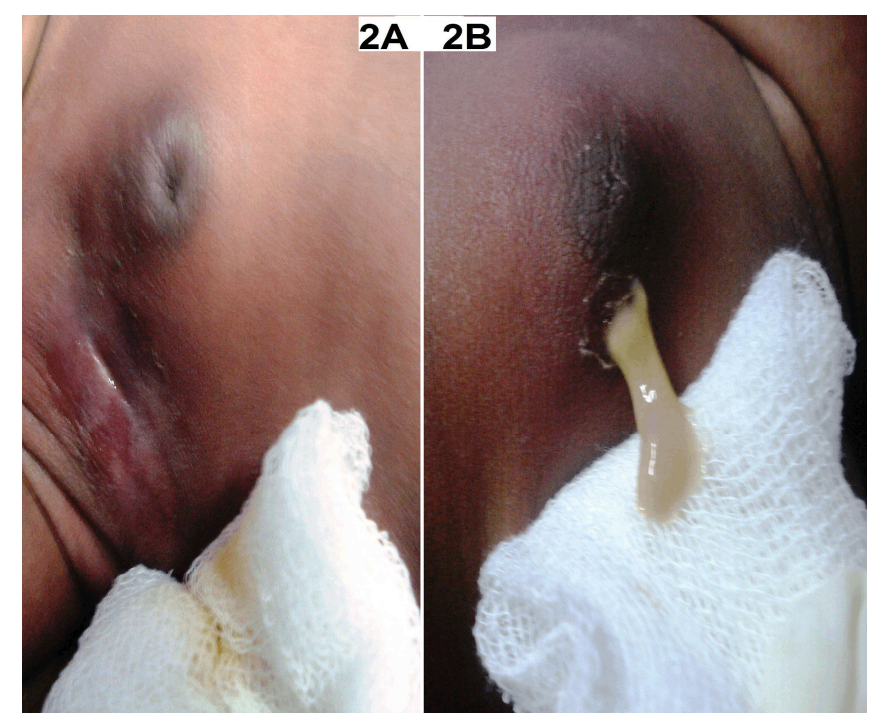

Figure 2: A) Incision and drainage from the right breast. B) Pus pouring out from the left breast.

prevent both local and systemic complications [7]. The patient was found to be active and healthy during the review visit after one week with no discharge of pus and completely normal breast.

$* * * * * * * * *$

\section{Author Contributions}

Arulkumaran Arunagirinathan - Conception and design, Acquisition of data, Analysis and interpretation of data, Critical revision of the article, Final approval of the version to be published

Jeyakumari Duraipandian - Conception and design, Acquisition of data, Analysis and interpretation of 
data, Drafting the article, Critical revision of the article, Final approval of the version to be published. Gopal Rangasamy - Conception and design, Acquisition of data, Analysis and interpretation of data, Drafting the article, Critical revision of the article, Final approval of the version to be published.

Smita Shivekar - Analysis and interpretation of data, Critical revision of the article, Final approval of the version to be published.

Prachi Saban - Analysis and interpretation of data, Critical revision of the article, Final approval of the version to be published.

Sunil Shivekar - Analysis and interpretation of data, Critical revision of the article, Final approval of the version to be published.

\section{Guarantor}

The corresponding author is the guarantor of submission.

\section{Conflict of Interest}

Authors declare no conflict of interest.

\section{Copyright}

(C) Jeyakumari Duraipandian et. al. 2011; This article is distributed under the terms of Creative Commons attribution 3.0 License which permits unrestricted use, distribution and reproduction in any means provided the original authors and original publisher are properly credited. (Please see www.ijcasereportsandimages.com /copyright-policy.php for more information.)

\section{REFERENCES}

1. Sainsbury R. (2008). Mastitis of infants. In: Williams NS, Bulstrode C.J.K., O'Connell P.R. eds. Bailey and Love's Short Practice of Surgery, 25th ed. Edward Arnold Ltd, 2008: 831-832.

2. Ramachandraiah A. Neonatal mastitis. Indian paediatrics 2000; 37:1021.

3. Borders H, Mychaliska G, Gebarski KS. Sonographic features of neonatal mastitis and breast abscess. Paeditric Radiol 2009; 39:955-958.

4. Rudoy RC, Nelson DN. Breast abscess during the neonatal period. A review. Am J Dis Child 1975; 129(9):1031-1034.

5. Efrat M, Mogilner JG, Iujtman H, Eldemberg D, Kunin J, Eldar S etal. Neonatal mastitis- diagnosis and treatment. Isr J Med Sci 1995; 31:558-560.

6. Walsh M, Mc Intosh K. Neonatal mastitis.Clin paediatric 1986; 25:395-399.

7. Stricker T, Navrati F, Sennhauser PH. Mastitis in Early infancy. Acta paediatrica 2005; 94:166-169. 